\title{
KINET: a social marketing programme of treated nets and net treatment for malaria control in Tanzania, with evaluation of child health and long-term survival
}

\author{
J. R. M. Armstrong Schellenberg ${ }^{1,3}$, S. Abdulla $^{1}$, H. Minja ${ }^{1}$, R. Nathan ${ }^{1}$, O. Mukasa ${ }^{1}$, T. Marchant ${ }^{1}$, \\ H. Mponda ${ }^{1}$, N. Kikumbih ${ }^{1}$, E. Lyimo ${ }^{1}$, T. Manchester ${ }^{2}$, M. Tanner ${ }^{3}$ and C. Lengeler ${ }^{3}{ }^{1}{ }_{\text {Ifakara Health }}$ \\ Research and Development Centre (IHRDC), P.O. Box 53, Ifakara, Tanzania, ${ }^{2}$ Population Services International, P.O. Box \\ 33500, Dar es Salaam, Tanzania; ${ }^{3}$ Swiss Tropical Institute, P.O. Box 4002, Basel, Switzerland
}

\begin{abstract}
We present a large-scale social marketing programme of insecticide-treated nets in 2 rural districts in southwestern Tanzania (population 350000 ) and describe how the long-term child health and survival impact will be assessed. Formative and market research were conducted in order to understand community perceptions, knowledge, attitudes and practice with respect to the products to be socially marketed. We identified Zuia Mbu (Kiswahili for 'prevent mosquitoes') as a suitable brand name for both treated nets and single-dose insecticide treatment sachets. A mix of public and private sales outlets is used for distribution. In the first stage of a stepped introduction 31 net agents were appointed and trained in 18 villages: 15 were shop owners, 14 were village leaders, 1 was a parish priest and 1 a health worker. For net treatment 37 young people were appointed in the same villages and trained as agents. Further institutions in both districts such as hospitals, development projects and employers were also involved in distribution. Promotion for both products was intense and used a variety of channels. A total of 22410 nets and 8072 treatments were sold during the first year: 18 months after launching, $46 \%$ of 312 families with children aged under 5 years reported that their children were sleeping under treated nets. A strong evaluation component in over 50000 people allows asscssment of the long-term effects of insecticide-treated nets on child health and survival, anaemia in pregnancy, and the costs of the intervention. This evaluation is based on cross-sectional surveys, and case-control and cohort studies.
\end{abstract}

Keywords: malaria, malaria control, insecticide-treated nets, net treatment, social marketing, child survival, Tanzania

\section{Introduction}

Despite malaria being the largest public health problem in Africa south of the Sahara, with over one million associated deaths each year (WHO, 1997), little progress has taken place in control during the past decades. Prompt treatment with an effective antimalarial remains the basis of malaria control strategies in most African countries (WHO, 1993). Preventive transmission control is being re-considered using insecticide-treated nets (ITNs, including treated bednets and curtains) which do not require a large national programme infrastructure for implementation. In a meta-analysis of African trials ITNs were found to reduce clinical malaria episodes by $48 \%$ and to improve anaemia status by an average $0.5 \mathrm{~g} / \mathrm{dL}$ (LENGELER, 1998). Most importantly, the regular use of ITNs under trial conditions prevents approximately 6 deaths for every 1000 children protected every year across a large range of transmission intensities. Many international agencies (e.g., UNICEF, WHO, World Bank, Organization of African Unity) have recognized that malaria control is an urgent priority in order to improve child survival and are now making plans for implementation of ITNs (WHO, 1996; UNICEF, 1998; USAID, 1998).

The translation of promising research results into effective public health action is a daunting task. There are at least 60 million children living in areas at risk for malaria in Africa and their nets, once provided, will need to be treated regularly (every 6-12 months) over many years. FEILDEN (1996) reviewed various options for financing and implementation of ITNs, most of which have been tried on a relatively small scale (up to 10 villages). These fall into 3 main implementation models: (i) the integration of ITN distribution into a community pharmacy network (e.g., the Bamako Initiative programme in Western Kenya (HILL, 1991), (ii) sales through local health units (e.g., FRASER-HURT \& LYIMO, 1998) or the existing primary health care system (D'AlESSANDRO et al., 1995)), and (iii) distribution through community groups (e.g., PREMJI et al., 1995). Despite much useful operational experience, it seems

Author for correspondence: Joanna Armstrong Schellenberg, IHRDC, P. O. Box 53, Ifakara, Tanzania;

e-mail ifakara.ihrdc@twiga.com premature to recommend specific large-scale ITN implementation strategies for the African continent. The launch of a number of large programmes (population of over 100000 ) using different pragmatic approaches will allow these strategies to be optimized.

Social marketing is a very flexible implementation model that has proved successful in resource-poor countries for interventions such as oral rehydration salts (ORS) and condoms (BASICS, 1998). Social marketing is an approach where the experience and methods of commercial marketing are applied to a product which has a social benefit, with the main motivation being social improvement rather than financial gain to the marketer (ANDREASEN, 1995). The approach usually uses a branded product that can be marketed and advertised professionally. Much attention is paid to the main target group - sometimes called customers - and much effort goes into understanding the perception, knowledge, attitudes and practices of this group. Social marketing entails an effective public-private partnership which may be particularly useful for ITNs: unlike drugs and vaccines, ITNs may be seen as a commercial commodity rather than a medical product. Social marketing of ITNs has recently been started in various African countries, for example, the Central African Republic (in 1996), Rwanda, Kenya and Zimbabwe (in 1997).

The long-term impact of ITNs on small children in areas with high malaria transmission (an arbitrary cut-off being an annual entomological inoculation rate over 100) remains a controversial issue. The potential consequences of delaying acquisition of immunity are worrying in that in such areas it has been suggested that overall survival could be better without ITNs (SNOw et al., 1997). However, good data on the issue are scant and the discussion has been based on indirect evidence. Following the discontinuation of malaria control trials in the past no evidence for a delay or a 'rebound' in mortality was found (MOLINEAUX \& GRAMICCIA, 1980; BRADLEY, 1991; GREENWOOD, 1997). Further, the indirect evidence presented to support the idea of a delay in child death in areas of high transmission has been questioned (D'ALESSANDRO \& COOSEMANS, 1997; LENGELER et al., 1997; LINES, 1997; MOLINEAUX, 1997). Only long-term randomized controlled trials could answer this question reliably but these would be 
unlikely to be ethical or acceptable to the communities involved. Not many alternative designs remain. One possibility is to compare users of ITNs to non-users in the frame of a large-scale programme: combining this estimate with information from coverage surveys would allow estimation of community effectiveness (LENGELER \& SNOW, 1996). Although the current debate does not warrant delaying the implementation of ITN programmes the issue needs to be addressed and monitored by more than one large-scale ITN programme.

We present an overview of the KINET (pronounced 'key-net') project in Tanzania. The project, based at the non-governmental Ifakara Health Research and Development Centre, has developed a social marketing system for getting nets and insecticide to a scattered rural population of 350000 people. A strong evaluation component in over 50000 people allows monitoring of the long-term effects of ITNs on health and child survival, together with an assessment of the costs of the intervention.

\section{Background}

Study area

Kilombero and Ulanga Districts lie in Morogoro Region in south-western Tanzania, about $320 \mathrm{~km}$ from Dar-es-Salaam (Fig. 1). Much of the area lies in the lowlying flood plain of the Kilombero River (average altitude $270 \mathrm{~m}$ ), which divides the 2 districts. The Udzungwa mountains lie to the northwest and there is also an upland area around Mahenge town (over $1000 \mathrm{~m}$ ). The area has a rainy season from November to May, although rain may fall in any month of the year. Annual rainfall range is approximately $1200-1800 \mathrm{~mm}$. The population is about 350000 , with an average density of about 10 people $/ \mathrm{km}^{2}$. There are 109 villages in the 2 districts, ranging in size from $<1000$ people to $>6000$. Average household size is about $5 \cdot 5$ people.

There is a wide mix of ethnic groups including Wandamba, Wapogoro, Wabena, Wabunga and Wahehe. Many local houses have mud walls and thatched roofs, while up to one-third have brick walls and corrugated

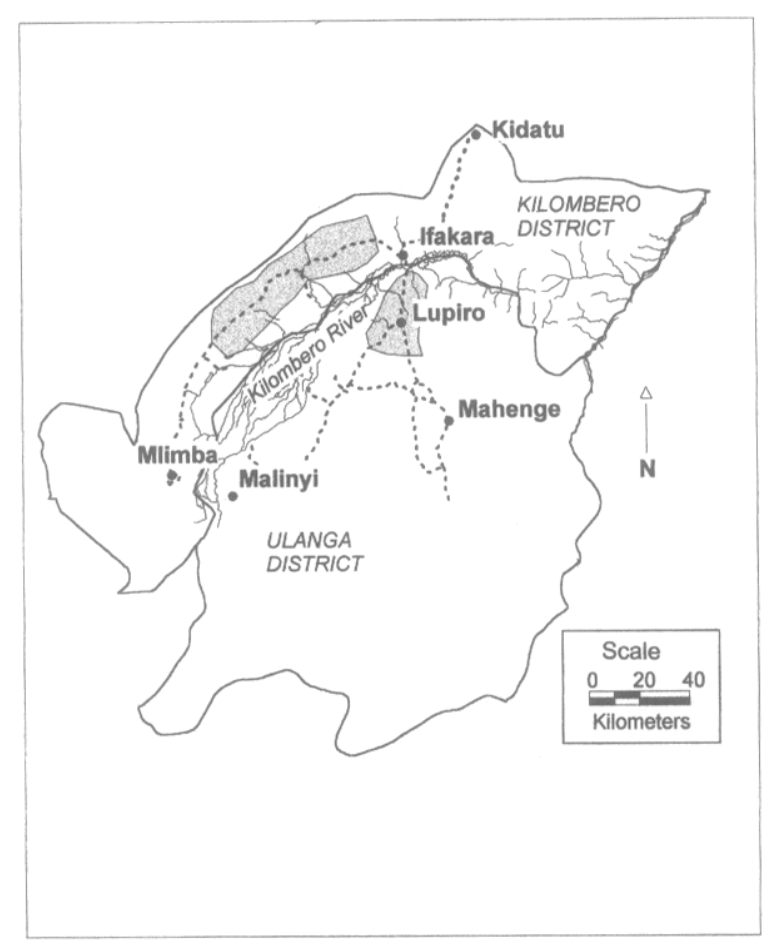

Fig. 1. The KINET programme area in Morogoro Region, south-western Tanzania. Shading indicates Phase 1 area (under demographic surveillance). The town of Ifakara is approximately $37^{\circ} \mathrm{E}$ and $8^{\circ} \mathrm{S}$. iron roofs. Rice, maize and cassava are commonly grown for home consumption. The main agricultural exports from both districts are rice, timber and charcoal. Fishing is also common, both for local consumption and for export as smoked fish to the towns of Morogoro and Dares-Salaam. Many families have a second house known as a shamba (farm) house in low-lying farmland areas where they stay during the rice-planting and harvesting seasons.

The public health system has a network of village health workers, health posts, dispensaries, health centres and hospitals with varying quality of care. In Ifakara town, the capital of Kilombero District, the main hospital is a large well-equipped mission Designated District Hospital. The hospital in Mahenge, the Ulanga District capital, has more limited facilities. There is a further mission hospital in Malinyi, serving the south-western part of Ulanga District. The mothcr-and-child health $(\mathrm{MCH})$ services are well developed and vaccination coverage is high with $78 \%$ children receiving all Expanded Programme on Immunization (EPI) vaccines by age 1 year (F. Font, personal communication). There are no paved roads and some villages are cut off for parts of the year by flooding. Limited seasonal bus services run up to 3 times each day between the towns of Ifakara, Mahenge and Malinyi. The TAZARA railway links the towns of Ifakara and Mlimba.

\section{Malaria and mosquito net use}

Malaria is the foremost health problem as reported through the health services and as perceived by local people, both for adults and children (TANNER et al., 1991). Malaria transmission due to Plasmodium falcipar$u m$ is intense and perennial, despite marked seasonality in mosquito densitics with a pcak in the rains. Anopheles gambiae and $A n$. funestus are the main vectors, with an estimated 200-300 infective bites per person per year occurring in rural areas close to Ifakara (SMITH et al., 1993). Life-threatening malaria in most of the area occurs largely in children, and commonly presents in those aged $<1$ year (SNOW et al., 1994).

A baseline survey conducted in 1996 found that $37 \%$ of households (3817/10299) had at least 1 net. The main motivation for their use was mosquito nuisance rather than malaria control, with use being widely reported as seasonal. A previous study at the Ifakara Health Research and Development Centre allowed preliminary assessment of various ways to distribute nets and net treatment in the area close to Ifakara town (FRASER-HURT \& LYIMO, 1998).

\section{The social marketing programme}

We describe here the background work preparing the social marketing campaign from July 1996 to May 1997, and then cover the issues of product, price, place and promotion.

\section{Sensitization and market research}

Sensitization meetings with village leaders were held in all the 18 villages of the Phase 1 distribution area (shaded area in Fig. 1). Each half-day meeting took the form of an open discussion between project and community leaders of the health problems of the community, ways to prevent malaria including ITNs, and the issues of how to get ITNs to the community in a sustainable way. The concepts of sustainability and cost recovery led to long discussions: most community leaders had no previous experience of projects that aimed for substantial cost recovery and found the concepts hard to understand. There was a common misconception that the Swahili term for 'project' ( mradi) involved being given things at little or no cost to the consumer.

An initial survey confirmed that virtually all people in the area knew of mosquito nets and that round and rectangular white polyester nets manufactured in Tanzania were generally available in the towns. Qualitative studies on community preferences for different types of 
net suggested that rectangular, dark green, high-quality polyester nets were likely to be popular. They were needed in 2 sizes $(180 \times 150 \times 100 \mathrm{~cm}$ and $180 \times$ $150 \times 130 \mathrm{~cm}$ ) in order to accommodate local sleeping patterns. People said they would prefer coloured nets to white nets since they would not need washing as often. Many people had heard of net treatment, owing to a previous UNICEF project in the area and to the availability of Rotary-funded treated nets in Ifakara (FRASERHURT \& LYIMO, 1998), but very few had tried it.

Further qualitative studies in 2 small villages found that malaria was often not perceived as a life-threatening problem, but as a fever-related illness which attacked all ages. This finding was confirmed by related work carried out at the same time in Ifakara town (HAUSMANNMUELA et al., 1998). Severe conditions perceived as causing child deaths, such as bandama (enlarged spleen), degedege (convulsions) and homa kali (high fever) were not widely thought to be caused by malaria. Consequently, it was decided to highlight messages related to malaria as a cause of child deaths, including those seen as bandama, degedege and homa kali, in promotion campaigns. Nuisance biting by mosquitoes was consistently felt to be a major problem and this was the main reason for people using mosquito nets. Few people were aware that malaria-transmitting mosquitoes were more likely to bite late at night than in the early evening: without this knowledge it is hard for people to understand how nets might prevent malaria.

We identified Zuia $M b u$ (Kiswahili for 'prevent mosquitoes') as a suitable brand name for both treated nets and insecticide treatment. This brand name and a logo for Zuia Mbu (Fig. 2) were developed together with an advertising agency in Dar-es-Salaam and tested locally. The brand and logo are used on all products and promotional materials.

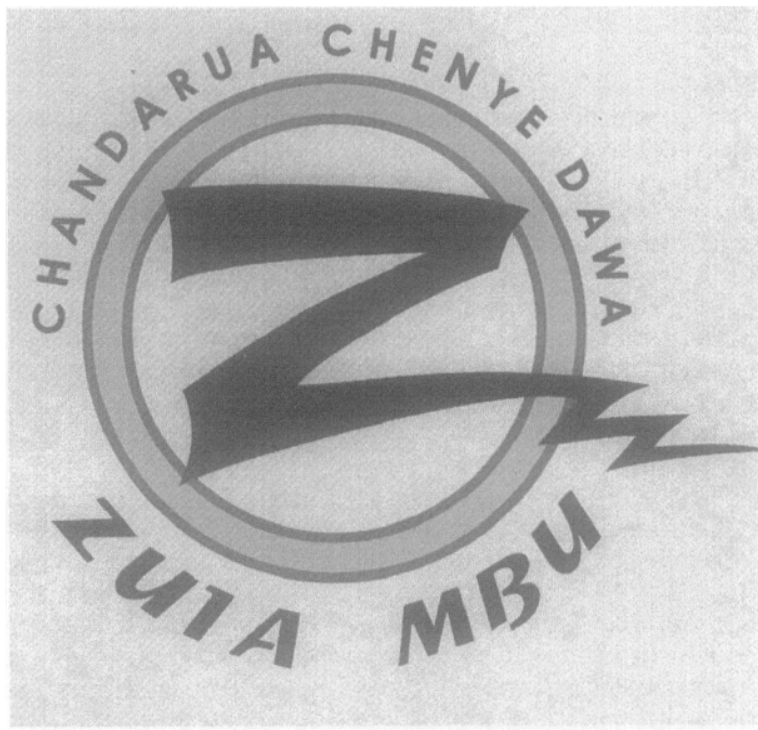

Fig. 2. The logo used for the Zuia Mbu brand used by the KINET programme.

\section{Products: nets and insecticide}

Dark green polyester 100-denier 156-mesh nets were obtained from Siamdutch Ltd, Thailand. Each net was pre-treated at the factory with $20 \mathrm{mg} / \mathrm{m}^{2}$ deltamethrin, and wrapped in a clear plastic bag with an insert containing information about $\mathrm{Zuia} \mathrm{Mbu}$.

The insecticide for net treatment was $2.5 \%$ lambdacyhalothrin CS (capsule suspension), a water-based micro-encapsulated formulation produced by Zeneca Ltd (UK). The insecticide was re-packaged by a collaborating project in Dar-es-Salaam in individual $6-\mathrm{mL}$ sachets, each containing enough to treat a single net of any locally available size (MILLER et al., 1998).

\section{Price}

Village sensitization meetings and experience from a previous project (FRASER-HURT \& LYIMO, 1998) suggested that local people would be willing to pay near cost recovery price for the nets, but rather less than costrecovery price for the insecticide. Retail prices were set at TSh 3000 ( US $\$ 5 \cdot 0$ ) for either size of net and TSh 250 $(\sim$ US $\$ 0.42$ ) for the insecticide treatment service. For nets, a commission of TSh $\mathbf{5 0 0}$ per net is paid to each retailer and a further commission of TSh 250 is paid to wholesalers. Thus the project recovers TSh 2250 ( $\sim$ US $\$ 3.75$ ) for each net sold, or about $66 \%$ of the replacement cost including transport to Ifakara and packaging. For insecticide, a commission of TSh 125 per sachet is paid to the retailers and a further TSh 25 to wholesalers. The project therefore recovers TSh 100 $(\sim$ US $\$ 0.17)$ for each sachet sold, about $17 \%$ of the replacement cost. Price control for nets, initially a particular worry of the community, is achieved by making the selling price clearly visible on the net packaging and by advertising the price widely.

\section{Place: the distribution system}

The social marketing of nets and insecticide was phased-in step-wise in 3 increasingly large areas. A flexible distribution system was chosen in conjunction with community leaders and community members in a series of open meetings. In the first phase, in each village 2 sales agents for nets and a further 2 mobile sales agents for insecticide were chosen regardless of the size of the village. The agents were nominated by the villagers themselves, and included health workers, parish priests, community leaders and shopkeepers. Net sales agents and net treatment agents were both given a 1-day training seminar, where they learnt how to treat nets and how to keep sales records. These records show the purchaser's name, balozi (local political leader), sub-village and village, and permit checks that the products have been sold within the study area. Twice-yearly re-training and review sessions are also held. The net treatment agents were given a distinctly painted $Z$ uia $M b u$ bicycle to assist with door-to-door sales, plastic basins, gloves, and plastic boxes for storage of sachets of insecticide. Nets and insecticide were initially supplied directly by project staff at weekly intervals, but as the project area enlarged a network of wholesalers was developed to keep agents supplied on a regular basis. Each agent has a contract with the Ifakara Health Research and Development Centre, and is paid on a commission basis (see 'Price' above). A reward system for reaching certain sales targets is also used. Agents who do not keep the terms of the contract are replaced.

\section{Promotion and the voucher system for pregnant women and} infants

A range of materials to support an information, education and communication (IEC) campaign was developed, including 3 posters (Fig. 3) and a leaflet. These materials, each incorporating ideas from the qualitative studies, were drawn by a local artist and pilot-tested extensively before printing and distribution to health clinics, sales outlets, etc. Billboards were posted along the main roads and one local bus had the Zuia Mbu logo painted prominently on its side. The project worked together with the District Health Management Teams in both districts in preparing the campaign.

A discount system to reduce further the cost of a net for mothers of young children and pregnant women was developed for use through health clinics. This system is intended to increase use of treated nets in those most at risk of severe effects of malaria. All women attending antenatal clinics and those attending for routine immunizations are entitled to a discount voucher which gives 


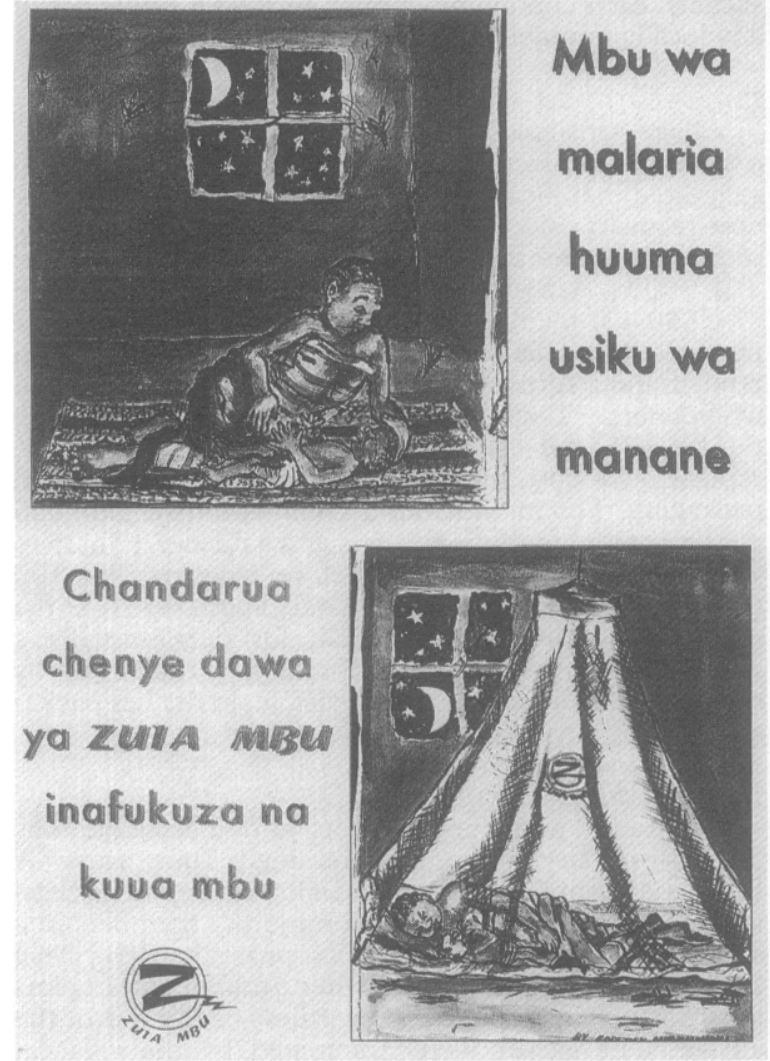

Fig. 3. One of the 3 posters developed for the treated net promotion campaign. This poster emphasizes the undisturbed sleep with the use of Zuia Mbu net. Translation: (1) Malariacarrying mosquitoes bite in the middle of the night, (2) Zuia $M b u$ treated nets repel and kill mosquitoes

them a TSh 500 (US $\$ 0.84$ or $17 \%$ retail value) price reduction for a treated mosquito net. Their clinic attendance card is marked to show that they have received the voucher. The voucher is then presented by the women to the net sales agent in their village. The sales agent then receives a credit from the project to the value of TSh 500 plus a TSh 50 handling charge.

\section{Public-private mix}

KINET uses a pragmatic mix of activities involving the public and private sectors. Such mixes have recently been advocated as an effective strategic approach for largescale ITN projects (USAID, 1998). KINET social marketing involves a collaboration between public entities such as the District Health Management Teams and the Ministry of Health, the private sector such as international suppliers and local business people, and the project social-marketing team.

\section{Launching and expansion}

The treated nets and insecticide treatment service were launched in 2 large villages on 24 and 25 May 1997 with celebrations including community theatre, songs, a raffle and speeches from community leaders. During the following week sales of nets and insecticide started in all the 18 Phase 1 villages. The project expanded to cover a further 8 villages in December 1997, 35 in June 1998, 18 in December 1998 and will cover the remaining 30 villages early in 1999 .

In order to facilitate this expansion in an efficient way, KINET is working to maximize inputs from local project partners such as local employers and mission hospitals. Project partners act as local distributors of Zuia Mbu nets and insecticide, using the same promotional materials and price structure, and as key players in the IEC campaign.
Project evaluation: the effect of ITNs on child health and survival

Socio-cultural aspects

Quantitative and qualitative work is being done, including periodic knowledge, attitude, beliefs and practices (KABP) studies, detailed community-based anthropological studies, and semi-structured interviews with sales agents and customers. This work allows a review of how IEC messages are received in the community and the chance to see which new messages might be useful. In addition, it allows evaluation of the discount system and the sales agents themselves, with a view to making improvements so that customers are served better by the project.

\section{Demographic surveillance system (DSS)}

This system was started in September 1996 and operates in the 18 Phase 1 villages covered by the study (shaded area in Fig. 1). This area has a population of some 55000 people living in 11000 households. A baseline census was carried out from September to December 1996. Name, sex, date of birth, and relationships within the household were recorded. Household locations were noted on sketch-maps. Rough locations of any shamba houses were also recorded. Since January 1997 every household has been visited every 4 months by an interviewer who updates the census record by asking about in- and out-migrations, pregnancies, births and deaths. The system developed originally in Navrongo (Ghana) by BINKA et al. (1998) was used with few modifications. Special surveys are added from time to time: for example, the first census round in 1997 was used to record socio-economic status in the household, and educational level for each household member. The DSS gives a full sampling frame for the Phase 1 area, within which vital events are monitored and random samples of households or individuals may be chosen for various in-depth studies.

\section{Effect of treated nets on child survival}

Two studies are under way within the DSS. First, a case-control study will assess risk factors for child mortality in the area, with a particular focus on use of nets, treated or untreated. Cases are children resident in the study area who died of any cause aged between 1 month and 5 years. Four controls are chosen for each case from the same area of residence and of approximately the same age. The case-control study will give an estimate of efficacy of the treated nets among children who use them. This can be combined with the coverage estimates from periodic surveys to estimate effectiveness in this target group.

The second study to assess the effect of treated nets on child survival is a birth cohort: all children born in 1998 and 1999 will be enrolled. At enrolment a questionnaire is used to elicit information on birthweight, mother's age and educational level, twinning, family size, birth order and birth interval. At subsequent routine DSS visits, a further brief questionnaire will be used to gather additional information. It is planned to follow these children until their 5th birthdays. Analysis will compare mortality rates in those using treated nets with those using untreated nets and those using no nets, allowing for any measured potential confounders.

\section{Effect of treated nets on anaemia and malaria in young children}

Three annual cross-sectional surveys to assess the effect of social marketing of treated nets on anaemia will be carried out on a random sample of children aged $<2$ years from the DSS area, one at baseline before the sale of the nets and then after the first and second year of implementation. A questionnaire is applied, a physical examination done and a blood sample obtained. The prevalence of anaemia will be compared between users 
and non-users of treated nets using logistic regression analysis to control for confounding.

To assess the effect of the interventions on malaria and anaemia episodes, a cohort of children aged $<5$ years residing in the village of Idete is being followed-up and their disease episodes documented, using a passive casedetection system at the village dispensary. Risk factors including treatment-seeking behaviour, household socio-economic status, use of treated nets and mother's education are being assessed by short questionnaires applied through routine DSS visits. Rate ratios of disease episodes (first/only episode) between those using treated nets and those not using them will be compared using Poisson regression to control for confounding. More detailed assessment of the impact of the interventions on malaria episodes is being done within this cohort using a nested case-control study.

Effect of treated nets on anaemia in pregnancy

A cross-sectional survey of pregnant women with rolling recruitment over a period of 12 months is also being carried out using the DSS. The study is designed to determine the prevalence of severe anaemia ( $\mathrm{Hb}$ $<8 \mathrm{~g} / \mathrm{dL}$ ) and to identify major risk factors for this anaemia, including use of treated nets.

Costing of implementation and willingness and ability to pay

Cost of the implementation to the provider is being assessed. Measures of effectiveness and costs will be combined in a cost-effectiveness analysis (CEA). The costs involved include the initial investment, recurrent costs, capital costs and opportunity costs. Each type of cost is identified by associated activities such as brand creation, promotion, training, distribution, etc. Willingness and ability to pay were elicited from a sample of respondents within and outside the Phase 1 area, who were asked about household expenditure patterns.

\section{Insecticide resistance: entomolngical indicators}

With increasing use of ITNs at community level, it is possible that the usual night-biting behaviour of the main vector of malaria in the area might change to peak in the early evening and early morning, when few people are in bed. Studies to assess changes in mosquito biting behaviour are therefore carried out every year together with bio-assays to monitor any trend in resistance of wild-caught $A n$. gambiae to lambdacyhalothrin or deltamethrin.

\section{First results}

Demography

The estimated mid-year (1997) population of the Phase 1 area was 54061 people living in 10966 households. Average household size is 4.9 people. Almost half $(44 \%)$ of the population is aged $<15$ years, $16 \%$ aged $<5$ years, and the sex ratio (M:F) is $1: 1 \cdot 02$. During 1997 the infant mortality rate was $95 / 1000$ live births (181/1902), and annual mortality in children aged 1-4 years was $14 \cdot 3 / 1000(98 / 6859$ child-years $)$. In children aged 5-9 years the annual mortality rate was $3.5 / 1000$ (28/7944 child-years). Total fertility was estimated at 4.7 births/woman.

\section{Willingness and ability to pay}

Of those interviewed, $69 \%(128 / 185)$ claimed to be willing to pay the price of US $\$ 5$ per net and $88 \%$ $(163 / 185)$ were willing to pay US $\$ 0.4$ per net for a net treatment service. Ability to pay assessed by median overall household expenditure in the month prior to the first survey was US\$74. Excluding expenditure on food, a median of US $\$ 7$ was spent on capital items and US $\$ 11$ was spent on other small items in the previous month. Many households have a bicycle $(34 \%)$ or radio (11\%). It should be noted that this survey was carried out in the harvest season, when expenditures are at their annual maximum. Further surveys are ongoing.

\section{Sales}

Thirty-one net sales agents and 37 mobile net treatment agents were appointed in May 1997 in the 18 villages of the first phase. Among the net agents there were 15 shop owners, 14 village leaders, 1 health worker, and 1 village priest. After 10 months, the priest and 3 village leaders were replaced: they were inactive, mainly owing to their other commitments. During the same period $10(27 \%)$ net treatment agents were no longer active and have been replaced.

The percentage of households with at least 1 net ruse from $37 \%$ at the end of 1996 to $52 \%(5913 / 11480)$ in mid-1998, by which time $24 \%(2730 / 11480)$ of households had at least 1 treated net and 48\%(4323/9040) nets were treated. Of a random sample of families with children aged $<5$ years, $46 \%$ reported that their children were sleeping under treated nets by April 1998. A total of 22410 nets and 8072 treatments were sold by the project during the first year. Sales records in the Phase 1 area suggest over $80 \%$ nets were sold to residents. As expected, demand peaked after the rains started, when mosquito populations rose dramatically: almost half of the total annual sales were during the months of December and January. Most net treatments were sold to owners of ordinary untreated nets: $31 \%$ of those who owned ordinary nets had treated these by December 1997 , whereas only $13 \%$ of Zuia Mbu net owners who had bought their nets at least 3 months previously had retreated their nets by December 1997.

There was a good response to the discount vouchers, with $26 \%(1687 / 6489)$ of net sales to Phase 1 area residents making use of the vouchers. Ongoing surveys will reveal whether the target group, i.e., pregnant women and those with young children, are the principal users of the discounted nets.

\section{Discussion}

Social marketing is a novel and promising approach to promote and supply effective malaria control tools. Its excellent track record for interventions as diverse as ORS, condoms and oral contraceptives suggests that it could perform well for the large-scale deployment of ITNs (USAID, 1998). So far the KINET project has achieved good coverage in a large highly endemic rural area, reinforcing positive experiences with social markcting of ITNs in the Central African Republic, Zimbabwe and Rwanda (A. Boner and L. Jamu, personal communication).

Large-scale ITN programmes will always be confronted with the problem of finding agents that are both trusted by the community and effective in selling ITNs. The initial choice of net and treatment agents rested largely with village leaders and this resulted in a great diversity of agents selling KINET products. Our early results suggest that commercial retailers often provide a better service to their communities than village leaders. Retailers are used to selling goods and usually have a larger working capital to invest in net and insecticide consignments. Further, they are available at most times of day and easy for potential customers to find. Future expansion is likely to increase the involvement of the private sector.

The issue of whether health facilities should also sell ITNs and treatments remains open, and there are no current Ministry of Health guidelines on this matter. With the gradual introduction of cost-sharing in Tanzania the selling of ITNs could find a natural place in the system but the issue of who should keep commission from the sales deserves careful consideration. An interesting contrast is seen in how sales commission is shared between $2 \mathrm{MCH}$ clinics selling ITNs in the KINET area (see also FRASER-HURT \& LYIMO, 1998). In one clinic all the staff participate in the sales and the TSh 500 commission on each sale is shared. In contrast, in the second clinic the rural medical aide in charge alone sells nets and keeps the commission; this has led to resent- 
ment among other staff and to less active promotion on their part.

In the interests of sustainability it is important to develop a system of wholesalers that follows the existing commercial system. This allows reduction of the intensive investment needed when all agents are supplied weekly by the project. The apparently lower cost-recovery to the project with wholesalers is more than offset by the lower distribution cost. Once an efficient wholesale network is established monthly supplies to wholesalers should be sufficient and the project can then easily expand to a wider area.

Nets were relatively common in our area before KINET sales started. We therefore started to promote and sell insecticide for net treatment as soon as possible so that existing nets might be treated. Informal feedback from the community suggests that people are often uneasy about bringing their nets out in public, and that they would prefer to treat their nets themselves. We have therefore introduced a home-treatment kit developed in Tanzania (MILLER et al., 1998), consisting of a singledose sachet of insecticide packaged with disposable gloves and locally developed instructions. The relatively high cost of this packaging is offset against the problems of deliberate or accidental misuse of larger quantities of insecticide, and the advantage that our target group prefer the freedom and privacy of treating their nets at home.

We chose to sell pre-treated nets rather than untreated nets despite the argument that this denies the opportunity of educating people at the time of purchase about the difference between a treated and an untreated net and how to treat a net. Pilot studies with the home-treatment kit suggest that people do not need special training to treat their nets. Selling pre-treated nets may mean that some people will not realize that they have bought a treated net, but we feel their lack of knowledge is an issue best tackled through ongoing targeted IEC concerning net treatment. For example, our treatment agents can make use of net sales records in order to make follow-up visits to those who have bought a net 3 months previously. They can then offer advice on malaria prevention and a net treatment service.

Two key issues remain on the promotion agenda. First, the sales are very seasonal, clearly peaking during the time of maximum mosquito densities. No detailed compliance measures are yet available but it is very likely that the net usage follows the same seasonal pattern. Since malaria transmission is perennial in the Kilombero Valley the all-year use of ITNs needs to be promoted actively. Secondly, KINET is aiming to reach a large and very dispersed rural population with 2 products: nets, for which existing demand is high, and insecticide, for which existing demand is much lower. Promotion will therefore focus increasingly on re-treatment of existing nets and new distribution channels may have to be developed to facilitate this.

An optimal balance between affordability, equity and full cost-recovery is difficult to achieve. KINET has a current low level of subsidy on the treated nets $(66 \%$ cost recovered) and a high level of subsidy on the insecticide ( $17 \%$ cost recovered). These costs do not cover a minimum programme infrastructure nor the cost of promotion: the project loses a substantial amount of money on every sale. As international demand for insecticide for net treatment increases it seems likely that cheaper formulations will become available and the cost of insecticide will decrease. Once a stable demand for nets and net treatment exists, retail prices may be increased towards full cost-recovery levels, with subsidies targeted exclusively through the public health sector using vouchers or in other ways.

Although full cost-recovery is an important consideration, there is more to sustainability than full costrecovery alone. Many ITN projects conducted in the past have not survived the end of their project status (e.g.,
HILL, 1991; PREMJI et al., 1995) despite a certain level of infrastructure and a banked revolving fund. Often procurement and ongoing distribution have been beyond the capacity of the local groups. One of the strengths of a public-private mix such as that used by KINET is the inherent sustainability of the private sector distribution system. The remaining issues of procurement and promotion are likely to need special attention at the end of the 'project status' phase. A low-cost social-marketing support service at district, regional or even national level could provide such inputs. Virtually no other intervention in preventive health is entirely self-supporting: if ITN programmes are (1) feasible on a large scale and (2) efficient through low delivery cost per net or per treatment, they should be able to attract sufficient donor support in the context of the Roll Back Malaria initiative.

The question of long-term effect of ITNs on survival in highly endemic areas is important. Since randomized controlled trials are neither feasible nor ethically acceptable, we have chosen observational studies to compare users of ITNs with non-users, both through a casecontrol study and the long-term follow-up of a birth cohort. Problems remaining include the difficulty of determining use of treated nets and the influence of potential confounders, many of which are difficult to measure. Experience from other areas of health, for example the health impact of smoking or the impact of ORS, suggests that observational studies can make a useful contribution. However, our results will need careful interpretation. Ideally, such long-term followup should be carried out in a number of sites. Other African projects are attempting to do this in Ghana and in Burkina Faso where the population formerly involved in the scientific trials (BINKA et al., 1996; HABLUETZEL et al., 1997) is being followed-up for a further 3 years in order to detect a possible delayed increase in mortality in the former intervention group compared to the former control group (F. Binka, personal communication; E. Sanogo, personal communication). A similar study is planned in Western Kenya (P. Phillips-Howard, personal communication).

The KINET project represents an attempt to see to what extent social marketing is a useful tool in the fight against malaria in a rural African setting. Data are being collected on the key issues of cost and effectiveness of ITNs on child survival, but the results are some time away. In the mean time, the information available to date suggests that social marketing is a useful approach for ITNs, being innovative, popular and sufficiently adaptable to address the varied challenges of a malaria control programme in a rural African setting.

\section{Acknowledgements}

We thank our many local collaborators, especially the District Councils and District Health Management Teams of Kilombero and Ulanga, without whose active and ongoing support the project would not be possible. We thank Andrew Boner of Population Services International for sharing with us his experiences from social marketing of treated nets in the Central African Republic. Wc arc also grateful to Dr Jane Miller for producing the insecticide sachets and for her ongoing inputs, to Mrs E. Lwilla for her many inputs into the project, to Don de Savigny for useful comments, and to the past and present Directors of IHRDC, Dr Andrew Kitua and Mr Hassan Mshinda, for their support. This paper is published with the permission of the Director-General of the Tanzanian National Institute of Medical Research.

KINET receives financial support from the Swiss Agency for Development and Co-operation, the Government of Tanzania and the UNDP/World Bank/WHO Special Programme for Research and Training in Tropical Diseases. C. L. is a recipient of a PROSPER senior scientist fellowship from the Swiss National Sciencc Foundation.

References

Andreasen, A. R. (1995). Marketing Social Change. San Francisco: Jossey-Bass.

BASICS (1998). Realizing the promise of a commercial 
approach to improving public health. Social Marketing Matters, a Newsletter for Marketers and Public Health-recommended Products. Arlington VA: BASICS, pp. 1-2.

Binka, F. N., Kubaje, A., Adjuik, M., Williams, L. A., Lengeler, C., Maude, G. H., Armah, G. E., Kajihara, B., Adiamah, J. H. \& Smith, P. G. (1996). Impact of permethrin impregnated bednets on child mortality in Kassena-Nankana district, Ghana: a randomized controlled trial. Tropical Medicine and International Health, 1, 147-154.

Binka, F. N., Ngom, P., Philips, J. F., Kubaje, A. \& MacLeod, B. (1998). Assessing population dynamics in a rural Africa society: the Navrongo Demographic Surveillance System. Demography. In press.

Bradley, D. J. (1991). Morbidity and mortality at Pare-Taveta, Kenya and Tanzania, 1954-66: the effects of a period of malaria control. In: Disease and Mortality in Sub-Saharan Africa, Feachem, R. G. \& Jamison, D. (editors). Oxford: Oxford University Press, pp. 248-262.

d'Alessandro, U., Olaleye, B., McGuire, W., Langerock, P., Bennett, S., Aikins, M. K., Thomson, M. C., Chan, M. K., Chan, B. A. \& Greenwood, B. M. (1995). Mortality and morbidity from malaria in Gambian children after introduction of an impregnated bednet programme. Lancet, 345, $479-483$.

d'Alessandro, U. \& Coosemans, M. (1997). Concerns on longterm efficacy of an insecticide-treated bednet programme on child mortality. Parasitology Today, 13, 124-125.

Feilden, R. M. (1996). Experiences of implementation. In: Net Gain-a New Method to Prevent Malaria Deaths, Lengeler, C., Cattani, J. A. \& de Savigny D. H. (editors). Ottawa: IDRC and WHO, pp. 55-110.

Fraser-Hurt, N. \& Lyimo, E. (1998). Insecticide-treated nets and treatment service: a trial using public and private sector channels in rural United Republic of Tanzania. Bulletin of the World Health Organization, 76, 607-615.

Greenwood, B. M. (1997). Malaria transmission and vector control. Parasitology Today, 13, 90-92.

Habluetzel, A., Diallo, D. A., Esposito, F., Lamizana, L., Pagnoni, F., Lengeler, C., Traoré, C. \& Cousens, S. N. (1997). Do insecticide-impregnated curtains reduce all-cause child mortality in Burkina Faso? Tropical Medicine and International Health, 2, 855-862.

Hausmann-Muela, S., Ribera, M. J. \& Tanner, M. (1998). Fake malaria and hidden parasites - the ambiguity of malaria. Anthropology and Medicine, 5, 43-61.

Hill, J. (1991). Evaluation of impregnated bednets distributed as part of the GOK/UNIC.FF malaria control programme in West Kabar. Nairobi, Kenya: UNICEF, Kenya Country Office.

Lengeler, C. (1998). Insecticide treated bednets and curtains for malaria control (a Cochrane Review). In: The Cochrane Library, Issue 3, 1998. Oxford: Update Software (CDROM version).

Lengeler, C. \& Snow, R. W. (1996). From efficacy to effectiveness: insecticide-treated bednets in Africa. Bulletin of the World Health Organization, 74, 325-332.

Lengeler, C., Smith, T. A. \& Armstrong Schellenberg, J. R. (1997). Focus on the effect of bednets on malaria morbidity and mortality. Parasitology Today, 13, 123-124.
Lines, J. D. (1997). Severe malaria in children and transmission control. Lancet, 315, 813.

Miller, J. E., Buriyo, A., Karugila, A. \& Lines, J. D. (1999). A new strategy for treating nets: Part 1 . Formulation and dosage. Tropical Medicine and International Health, 4, 160-166.

Molineaux, L. (1997). Nature's experiment: what implications for malaria prevention?. Lancet, 349, 1636-1637.

Molineaux, L. \& Gramiccia, G. (1980). The Garki Project. Research on the Epidemiology and Control in the Sudan Savannah of West Africa. Geneva: World Health Organization.

Premji, Z., Lubega, P., Hamisi, Y., Mchopa, E., Minjas, J., Checkley, W. \& Shiff, C. (1995). Changes in malaria associated morbidity in children using insecticide treated mosquito nets in the Bagamoyo District of Coastal Tanzania. Tropical Medicine and Parasitology, 46, 147-153.

Smith, T., Charlwood, J. D., Kihonda, J., Mwankusye, S., Billingsley, P., Meuwissen, J., Lyimo, E., Takken, W., Teuscher, T. \& Tanner, M. (1993). Absence of seasonal variation in malaria parasitaemia in an area of intense seasonal transmission. Acta Tropica, 54, 55-72.

Snow, R. W., Bastos de Azevedo, I., Lowe, B. S., Kabiru, E. W., Nevill, C. G., Mwankusye, S., Kassiga, G., Marsh, K. \& Teuscher, T. (1994). Severe childhood malaria in two areas of markedly different falciparum transmission in east Africa. Acta Tropica, 57, 289-300.

Snow, R. W., Omumbo, J. A., Lowe, B., Molyneux, C. S., Obiero, J. O., Palmer, A., Weber, M. W., Pinder, M., Nahlen, B., Obonyo, C., Newbold, C., Gupta, S. \& Marsh, K. (1997) Relation between severe malaria morbidity in children and level of Plasmodium falciparum transmission in Africa. Lancet, 349, 1650-1654.

Tanner, M., De Savigny, D., Mayombana, Ch., Hatz, C., Burnier, E., Tayari, S. \& Degremont, A. (1991). Morbidity and mortality at Kilombero 1982-88. In: Disease and Mortality in Sub-Saharan Africa, Feachem, R. G. \& Jamison, D. T. (editors). Oxford: Oxford University Press, pp. 286-305.

WHO (1993). Implementation of the global malaria control strategy. Report of a WHO study group on the implementation of the global plan of action for malaria control 19932000. WIIO Technical Report Series 839. Geneva: World Health Organization.

WHO (1996). Insecticide impregnated materials in the African Region. Report of a meeting in Brazzaville, 18-20 March 1996. Brazzaville: World Health Organization.

WHO (1997). World malaria situation in 1994. Weekly Epidemiological Record, 72, 269-290.

UNICEF (1998). Malaria control. Report from an informa consultation on malaria control, 18-20 June 1997. New York: UNICEF.

USAID (1998). Proceedings of the International Conference on Bednets and Other Insecticide-treated Materials for the Prevention of Malaria, October 29-31, 1997. Washington D. C.: USAID.

Received 23 September 1998; revised 25 fanuary 1999; accepted for publication 2 February 1999 